\title{
Plasma blood group changes in gastrointestinal tract carcinoma
}

\author{
Ph. ROUGer 1 , D. RiveAu ${ }^{1}$, Ch. SALMON 11 , AND J. LOYGUE 2 \\ From the ${ }^{1}$ National Blood Group Reference Laboratory, INSERM U76 CNTS, 53 Boulevard Diderot, \\ 75571 Paris, and the ${ }^{2}$ Department of Surgery, Hopital Saint Antoine, 184 rue du Faubourg Saint-Antoine, \\ 75012 Paris, France
}

SUMmary The levels of A, H, I, and i plasma antigens and of anti-B, anti-I, and anti-T antibodies were measured in 70 subjects with colonic or gastric carcinoma. These studies showed a significant increase in A plasma activity of the A subjects, and in $\mathrm{H}$ plasma activity of the $\mathrm{O}$ subjects, while $25 \%$ of the tested subjects showed increased I plasma activity. There was no difference in i plasma activity between cancer patients and healthy subjects. These results take into account the marked polymorphism acquired by neoplastic tissue, which is capable also of producing a greater quantity of antigens than that of healthy subjects. Nevertheless this heterogeneity forms a barrier to the clinical measurement of these plasma antigens for screening neoplasms. The significant fall in the amount of anti-T antibodies seemed to be secondary to the absorption of these antibodies on the surface of the tumour cells.

Many authors (Salmon and Malassenet, 1960; Saeed and Fine, 1968) have reported an excess of A, B, and $H$ substances in the plasma of patients with gastrointestinal tract neoplasms. The $\mathrm{A}, \mathrm{H}, \mathrm{Le}^{\mathrm{a}}$, and $\mathrm{T}$ glycosyltransferases were proved to be present in colonic tumour cells on culture (J. P. Cartron, 1978, personal communication).

On the other hand, Davidsohn et al. (1971) and Feizi (1978) demonstrated the disappearance of A, $B$, and $\mathbf{H}$ substances in the tumour cells of the gastrointestinal tract, whereas the $\mathbf{I}$ substance seemed to be present in an abnormally high quantity (Feizi, 1978). (I antigen could be a precursor of the biosynthesis of $\mathrm{H}$ antigen.) Stellner et al. (1973) showed, in adenocarcinoma cells, the disappearance of enzyme activities capable of transforming $\mathrm{H}_{1}$ glycolipids into A or B glycolipids.

The present study was undertaken to find out if the modifications seen in tumour tissue from the gastrointestinal tract had any effect on the level of $\mathrm{A}, \mathrm{H}, \mathrm{I}$, and $\mathrm{i}$ substances and anti-B, anti-I, and anti- $T$ antibodies in the serum in order to investigate the potential value of their use in cancer screening.

\section{Material and methods}

The titration of $\mathrm{A}, \mathrm{H}, \mathrm{I}$, and i plasma antigens is based on the inhibition of haemagglutination. The

Received for publication 6 March 1979 basic agglutination must be as weak as possible, but at the same time detectable in the used system. The agglutination obtained with a low-antibody concentration can thus be inhibited by a low-substance concentration.

Increasing dilutions of plasma were mixed for 2 hours at $20^{\circ} \mathrm{C}$ with a constant antibody concentration (inhibition phase). After fixation the amount of free antibodies was measured by their ability to agglutinate specific red cells. The agglutination phase of non-treated red cells was performed in a manifold combined with an autoanalyser (Rouger $e t$ al., unpublished observation (Fig.1).

Plasma dilutions mixed with antibodies were pumped and flowed in a reaction coil. A red blood cell solution and PVP were added. This mixture reacted for 30 minutes. The reaction coil was at $10^{\circ} \mathrm{C}$ or $15^{\circ} \mathrm{C}$, according to the system used (Table 1). After double decantation, the residual red cell concentration was determined in a continuous flow counter, and the results were recorded with a pen recorder.

From the results obtained, we calculated the agglutination percentages for the chosen dilutions. The agglutination percentage curve, expressed in terms of logarithms of tested plasma dilutions, was a sigmoid, which was linearised by probit-logarithm transformation. Each tested plasma was referred to a standard inhibitory solution. The reference solution contained 100 arbitrary inhibition units 907 


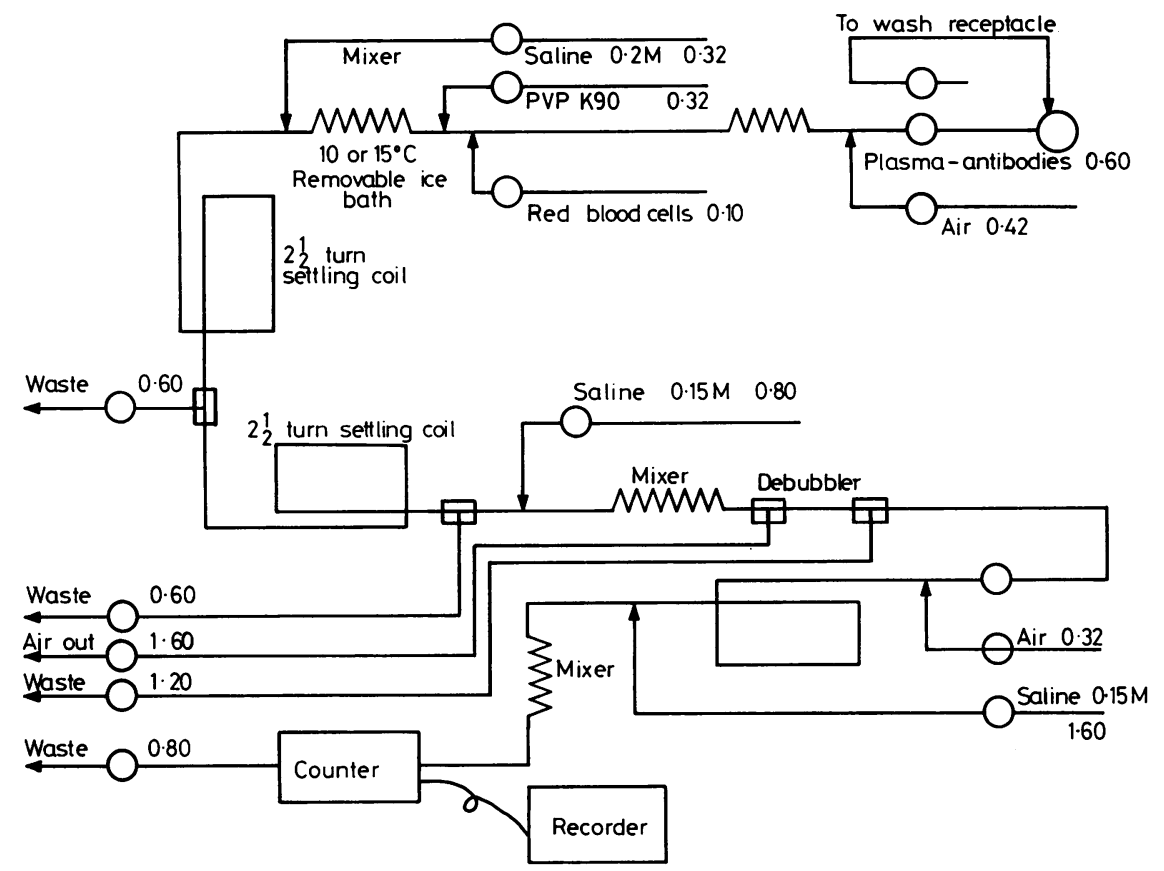

Fig. 1 A schematic flow diagram of the circuit used for the titration of $A, H, I$, and $i$ antigens.

(AIU). The comparison obtained between the tested plasma and the reference solution allowed the determination of the number of AIUs present in the tested plasma. The reproducibility of these tests was confirmed by repeated measurements of the same plasma at the same dilutions. The variation observed did not exceed $20 \%$.

The concentrations of anti-B and anti-I antibodies were measured in an AutoAnalyzer using bromelintreated red cells (B cells at $15^{\circ} \mathrm{C}$ for anti-B activity and $\mathrm{O}$ red cells at $4^{\circ} \mathrm{C}$ for anti-I activity). The concentration of antibodies was measured in the same way with the help of neuraminidase-treated $\mathrm{O} \cdot \mathrm{i}$ red cells at $20^{\circ} \mathrm{C}$.

The secretor status of each subject was determined by the study of $\mathrm{A}, \mathrm{B}$, or $\mathrm{H}$ substances in the saliva.

Thus 70 subjects with gastric or colonic cancers without metastasis were tested. The diagnosis was confirmed by histological examination after surgery. Each pathological population was compared with a healthy population (180 subjects). Both the healthy and cancer populations were identical as far as age and sex were concerned (patients were aged between 25 and $65 ; 50 \%$ were men and $50 \%$ were women).

Table 1 Some technical aspects of $A, H, I$, and $i$ antigen titration

\begin{tabular}{|c|c|c|c|c|}
\hline & \multicolumn{4}{|l|}{ Plasma activities } \\
\hline & $A$ & $\boldsymbol{H}$ & $I$ & $i$ \\
\hline \multicolumn{5}{|l|}{ Temperature $\left({ }^{\circ} \mathrm{C}\right)$} \\
\hline Inhibition & 20 & 20 & 20 & 20 \\
\hline Agglutination & 15 & 10 & 15 & 15 \\
\hline$\%$ PVP & 1.5 & 1 & $1 \cdot 5$ & 1 \\
\hline \multicolumn{5}{|l|}{ Antibodies } \\
\hline Type & Anti-A (pool) & Anti-H (CER) (1) & Anti-I (ABG) (2) & Anti-I (PEA) \\
\hline Dilution & $1 / 24$ & $1 / 21$ & $1 / 10500$ & $1 / 100$ \\
\hline Red blood cells & $\mathbf{A}_{2}$ & & OI & Oi (cord) \\
\hline Reference inhibitory activities & $\begin{array}{l}\text { A substance from pig } \\
\text { and horse stomach }\end{array}$ & $\begin{array}{l}\text { O saliva pool } O \text { and } A_{2} \\
\text { sera pool }\end{array}$ & O sera pool & $O$ and $A_{2}$ sera pool \\
\hline Remarks & & & $\begin{array}{l}\text { Treatment of plasma } \\
\text { by } 2 \text { mercapto-ethanol } \\
0 \cdot 2 \mathrm{M}\end{array}$ & \\
\hline
\end{tabular}

(1; $B_{h}$ subject; (2) Auto-immune haemolytic anaemia 
Table $2 H$ plasma antigen according to the secretor status of patients with gastrointestinal tract carcinoma and controls (only $O$ phenotype subjects)

\begin{tabular}{lcclll}
\hline & Healthy subjects & & \multicolumn{2}{l}{$\begin{array}{l}\text { Subjects with } \text { GIT } \\
\text { carcinoma }\end{array}$} \\
\cline { 2 - 3 } \cline { 5 - 6 } \cline { 5 - 6 } & $n$ & Mean value & & $n$ & Mean value \\
\hline Secretor & 31 & 168 & & 19 & 201 \\
Non-secretor & 9 & 76 & & 7 & 187 \\
Total & 40 & $111 \cdot 5$ & & .26 & 197 \\
\hline
\end{tabular}

$\mathbf{n}=$ number of subjects tested

\section{Results}

\section{A PLASMA ANTIGEN}

A plasma activity in group $A\left(A_{1}\right.$ and $\left.A_{2}\right)$ subjects with cancer of the gastrointestinal tract appeared significantly higher than that in healthy subjects of the same group (Fig. 1) (P 0.001).

The average values were 70 and $140 \mathrm{AIU}$ for the healthy and cancer subjects respectively.

\section{H PLASMA ANTIGEN}

$H$ plasma activity in group $\mathbf{O}$ subjects with gastrointestinal tract neoplasms was significantly higher

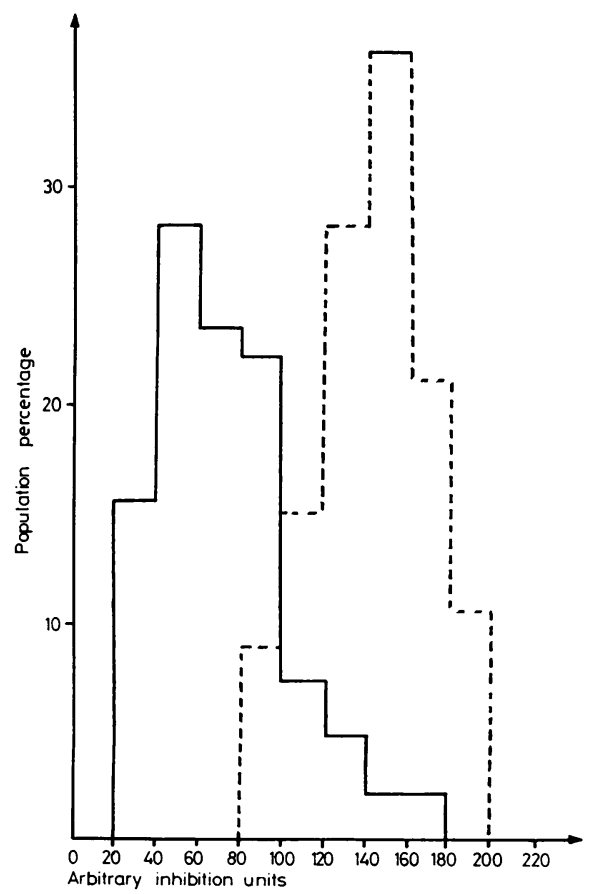

Fig. 2 A plasma activity is higher in patients with a gastrointestinal tract carcinoma than in the normal population ( - normal subjects (64); --- subjects with G I T carcinoma (22)).

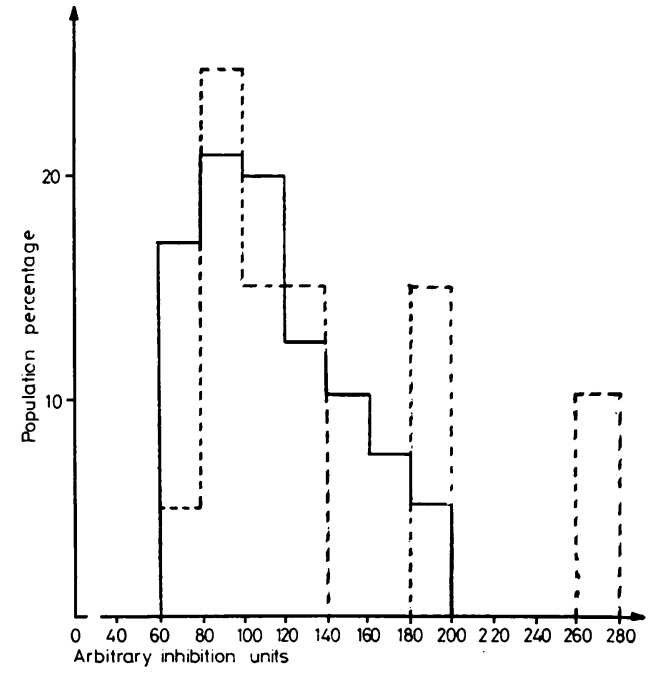

Fig. 3 Comparative study of I plasma antigen in normal subjects $(-39)$ and subjects with $G I T$ carcinoma (--- 38).

than that in healthy group $O$ subjects $(P 0.01)$. On the other hand, $\mathbf{H}$ plasma activity in $\mathbf{A}_{1}$ subjects was identical in the two populations. In the healthy subjects, $A$ and $H$ activities were dependent on Lewis and secretor phenotypes, while the abnormal $A$ and $H$ activities in cancer subjects were independent of these systems (Table 2).

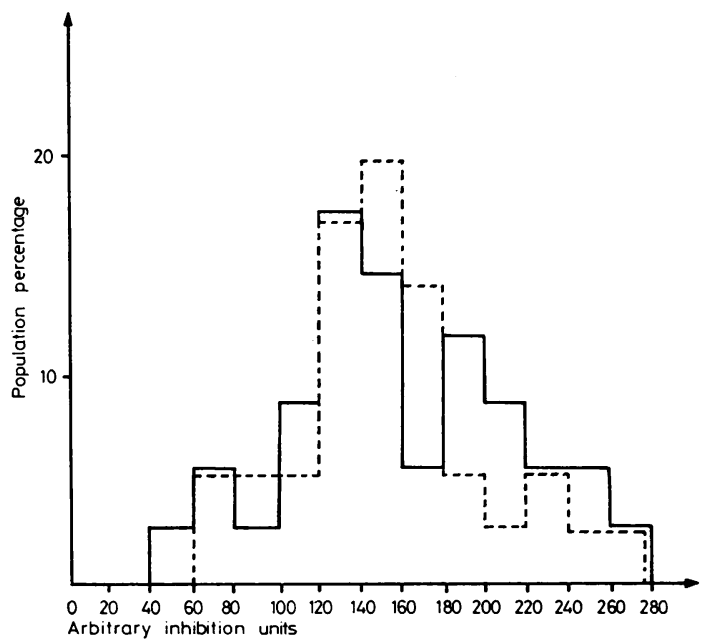

Fig. 4 Comparative study of $i$ plasma antigen in normal subjects (-33) and subjects with G I T carcinoma (-- 34). 
Table 3 Anti-T, anti-I, and anti-B levels in normal subjects with gastrointestinal carcinomas

\begin{tabular}{clll}
\hline & Healthy subjects & $\begin{array}{l}\text { Subjects with GIT } \\
\text { carcinomas }\end{array}$ & \\
\hline Anti-T & & & \\
$<100$ units & $16(23)$ & $12(46)$ & P 0.02 \\
$>100$ units & $52(77)$ & $14(54)$ & \\
Anti-I & & $18(69)$ & NS \\
$<50$ units & $40(59)$ & $8(31)$ & \\
$>50$ units & $28(41)$ & $20(77)$ & NS \\
Anti-B & & $6(23)$ & \\
$<200$ units & $50(73)$ & & \\
$>200$ units & $18(27)$ & & \\
\hline
\end{tabular}

Percentages are shown in parentheses

I AND i Plasma ANTIGENS

The distribution of I plasma activity in patients with cancer of the stomach and colon appeared to be different from the observed distribution in healthy subjects. Of the cancer subjects tested, $25 \%$ had an I activity of more than 180 units, while only $5 \%$ of the healthy subjects showed values of more than 180 AIU (Fig. 2). On the other hand, i activity was identical in the two populations (Fig. 3). The I and i plasma activities were independent of the Lewis and secretor phenotypes in both the healthy and cancer subjects.

The levels of anti-B and anti-I were identical in both the healthy and cancer populations, while the level of anti-T antibodies was significantly lower in the patients with gastric and colonic cancers (P 0.02). No difference could be detected in the levels of these antibodies between subjects with gastric and colonic carcinomas (Table 3).

\section{Discussion}

The methodological problems posed by the detection and dosage of $\mathrm{A}, \mathrm{H}, \mathrm{I}$, and i plasma activities have already been discussed (Rouger et al., unpublished observations).

If numerous tissues are capable of producing $\mathbf{A}$ and $\mathrm{H}$ antigens, especially in gastric and colonic tissues (Szulman, 1962), the cells producing the A, H, I, and i plasma substances have still not been identified, perhaps due to the large number of cell types involved. Even if the tumour cells are directly responsible for the synthesis of an excess of $A$ and $\mathrm{H}$ substances, the consequence at the plasma level could be moderated more often due to the vascular space, which is an important dilution factor.

Nevertheless the increased $\mathrm{A}, \mathrm{H}$, and I plasma antigens in certain cancer subjects could be due to the neoplastic cells overproducing $\mathrm{A}, \mathrm{H}$, and I substances, the biochemical support of which has not yet been precisely defined.

Some authors (Barber and Dunsford, 1959; Salmon and Malassenet, 1960; Saeed and Fine, 1968) have described an excess of ABH substances in the plasma of cancer subjects (epithelium, ovary, stomach, pancreas). In these exceptional observations, the amount of $\mathrm{A}$ or $\mathrm{H}$ substance was particularly high, almost the same as the quantity of A or $H$ substance in the saliva. The increases of $A$ and $H$ plasma activity shown in this study are much less than those described in these rare cases. The substances and blood group enzymes have been shown in tumour cells on culture. In the HT 29 cellular line from a cancer of the colon, Cartron (1978, personal communication) demonstrated $\mathrm{A}, \mathrm{H}, \mathrm{Le}^{\mathrm{a}}$, and $\mathrm{T}$ glycosyltransferase activities. In the BOT 2 line (Anglin et al., 1977), originating from a breast cancer, glycoproteins with blood group activity were present in the culture medium. In the HeLA line, cells in culture possess $\mathrm{H}$ specificity (carried by the glycoproteins, notably CEA) and can be converted in vitro in A or B specificity (Pann and Kuhns, 1972; Mousseron-Canet et al., 1975; Bali et al., 1976). These results take into account the persisting activity of the synthesis of blood group substances of the tumour cells on the one hand and the marked polymorphism of the different cells on the other.

Elsewhere, many authors (Nairn et al., 1962; Davidsohn et al., 1969; Davidsohn and Ni, 1969; Davidsohn et al., 1971; Lill et al., 1976; Lin et al., 1977) have shown that there is more often a weakened $\mathrm{A}, \mathrm{B}$, or $\mathrm{H}$ activity in gastric adenocarcinoma and a high I activity; but, in fact, each tumour studied possessed a particular profile with regard to $\mathrm{ABH}$ activities.

There is no correlation between the levels of $\mathrm{A}, \mathrm{H}$, and $I$ in the plasma of a cancer subject. These results obtained in plasma 'far from the tumour' take into account the polymorphism already described for tumour tissues and tumour cells on culture, as far as the haemagglutination inhibition has allowed the 'inhibitor activities' to be shown, without regard to their biochemical support.

This heterogeneity forms a barrier to the dosage of A, H, I, and i plasma activities for screening gastrointestinal tract neoplasms, apart from a few exceptional cases.

As far as anti-T is concerned, we found almost the same data as Springer et al. (1977), but this is probably not useful in the detection of carcinoma. The normal anti-B and anti-T antibodies might result predominantly from continuous antigenic stimulation by intestinal flora; the difference between anti-T and anti-B shows that the immunological function is normal and that the anti-T decrease could be related to absorption on tumour cells, on the membranes of which the $T$ antigen is well developed. Springer et al. (1977) have shown the same phenomenon in breast cancers and have tried 
to stimulate the production of anti-T by inducing active immunotherapy.

We thank Mr Pierre Gane for technical assistance. This work was supported by research grant ATP 56 7888 from the National Institute of Health and Medical Research (INSERM, France).

\section{References}

Anglin, J. H., Jr., Lerner, M. P., and Nordquist, R. E. (1977). Blood group-like activity released by human mammary carcinoma cells in culture. Nature, 269, 254-255.

Bali, J. P., Magous, R., Lecou, C., and Mousseron-Canet, M. (1976). Presence of blood group $H$ antigen on a carcinoembryonic antigen, and its enzymatic modification into blood group A and B specificities. Cancer Research, 36, 2124-2129.

Barber, M., and Dunsford, I. (1959). Excess of bloodgroup substance $A$ in serum of patients dying with carcinoma of the stomach. British Medical Journal, 1, 607-609.

Davidsohn, I., Kovarik, S., and Ni, L. Y. (1969). Isoantigens $A, B$, and $H$ in benign and malignant lesions of the cervix. Archives of Pathology, 87, 306-314.

Davidsohn, I., and Ni, L. Y. (1969). Loss of isoantigens $\mathrm{A}, \mathrm{B}$, and $\mathrm{H}$ in carcinoma of the lung. American Journal of Pathology, 57, 307-334.

Davidsohn, I., Ni, L. Y., and Stejskal, R. (1971). Tissue isoantigens $\mathbf{A}, \mathbf{B}$ and $\mathbf{H}$ in carcinoma of the stomach. Archives of Pathology, 92, 456-464.

Feizi, T. (1978). The I and i antigens on certain normal and pathologic tissues. Revue Française de Transfusion et Immuno-Hématologie, 21, 165-174.

Lill, P. H., Norris, H. J., Rubenstone, A. I., Chang-Lo, M., and Davidsohn, I. (1976). Isoantigens ABH in cervical intraepithelial neoplasia. American Journal of Clinical Pathology, 66, 767-774.

Lin, F., Liu, P. I., and McGregor, D. H. (1977). Isoanti- gens $\mathrm{A}, \mathrm{B}$, and $\mathrm{H}$ in morphologically normal mucosa and in carcinoma of the larynx. American Journal of Clinical Pathology, 68, 372-376.

Mousseron-Canet, M., Magous, R., Lecou, C., and Levallois, C. (1975). Enzymatic modification of the transplant antigens (ABO system) on human tumor cells. Cancer, 36, 1309-1314.

Nairn, R. C., Fothergill, J. E., McEntegart, M. G., and Richmond, H. G. (1962). Loss of gastro-intestinalspecific antigen in neoplasia. British Medical Journal, 1, 1791-1793.

Pann, C., and Kuhns, W. J. (1972). Differentiation of $\mathrm{HeLa}$ cells with respect to blood group $\mathrm{H}$ antigen. Nature New Biology, 240, 22-24.

Saeed, S. M., and Fine, G. (1968). Excessive serum levels of $A$ and $H$ substances in a patient with gastric carcinoma. Transfusion, (Philadelphia) 8, 179-183.

Salmon, Ch., and Malassenet, R. (1960). A propos des substances $\mathrm{ABO}$ présentes en grande quantité dans le sérum humain. Deux nouvelles observations. Transfusion (Paris), 3, 91-94.

Springer, G. F., Desai, P. R., Yang, H. J., Schachter, H., and Narasihman, S. (1977). Interrelations of blood group $M$ and precursor specificities and their significance in human carcinoma. In Human Blood Groups Proceedings of the 5th International Convocation of Immunology, Buffalo, New York), edited by J. F. Mohn, R. W. Plunkett, R. K. Cunningham and R. M. Lambert, pp. 179-187. Karger, Basle.

Stellner, K., Hakomori, S. I., and Warner, G. A. (1973). Enzymic conversion of $\mathbf{H}_{1}$-glycolipid to A or B-glycolipid and deficiency of these enzyme activities in adenocarcinoma. Biochemical and Biophysical Research Communications, 55, 439-445.

Szulman, A. E. (1962). The histological distribution of the blood group substances in man as disclosed by immunofluorescence. II. The $\mathrm{H}$ antigen and its relation to A and B antigens. Journal of Experimental Medicine, 115, 977-996.

Requests for reprints to: Ph. Rouger, Centre National de Transfusion Sanguine, 53 Boulevard Diderot, 75571 Paris, Cedex 12, France. 